\title{
¿Qué importancia le asigna a la educación en dicha estrategia y qué opinión le merece la calidad de la educación en el pais?
}

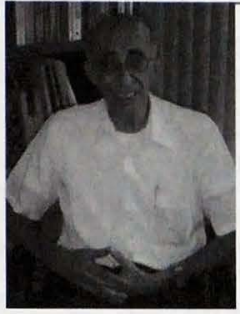

Javier lbisate, UCA

Uno de los problemas estructurales de nuestras sociedades es que, de la misma manera que existe una gran desigualdad en los ingresos (coeficiente de Gini), también ha existido una desigualdad sensible en los niveles de educación. El hecho de haber sido por largas décadas economfas agrarias monoexportadoras ha generado un déficit inculpable de educación en las clases campesinas. Basta ver que el "machete" ha sido y sigue siendo en gran parte la herramienta típica del sector rural, es decir, se trata de un modo de producción primario y primitivo, que no ha exigido mayor nivel de educación escolar para realizar esas tareas, a excepción de la destreza física. No se ha entrado en la civilización del arado, desde el punto de vista técnico, y tampoco los campesinos han tenido la oportunidad de gerenciar grandes fincas y asi adquirir una educación administrativa. Los niveles de educación requieren un cierto nivel de ingresos que la hagan posible; por ello el nivel de educación guarda cercana relación con el desigual nivel de ingresos.

En el orro extremo las clases altas de la sociedad han tenido la oportunidad de formarse profesionalmente en buenas universidades nacionales y extranjeras y ejercer dichas profesiones en las mejores empresas nacionales o extranjeras, e incluso pueden emigrar al exterior para comperir en instituciones internacionales. $\mathrm{Al}$ mismo tiempo, dentro del pals, nos encontramos con el problema de que quizás haya "demasiadas universidades" (buenas o medianas) para formación de cuellos blancos y muy pocas" "escuelas profesionales" para formación de uñas azules, trabajadores manuales.

Pese a los avances realizados por los ministerios de Educación y tomando en cuenta los da ños causados por los terremotos del 2001 a tantos centros educativos, lo cierto es que los presupuestos nacionales no han dado la suficiente atención a rubro educación, en sí mismo o si lo comparamos con países cercanos como Costa Rica. La inversión extranjera (excepto la rutinaria maquila textil) no llegará al pafs si no cuenta con mano de obra calificada.

Tanto los programas del PNUD (Informes de desarrollohumano) como los programas de Fusades en estas políticas, of reciendo suficientes datos sobre la situación de la educación nacional y regional. Por supuesto los informes más recientes del Banco Mundial insisten en esta inversión. ¿Cómo financiarla? En parte, reduciendo el presupuesto del ejército y transfiriendo sus fondos a educación de la juventud. Una vez más, habrá que acudir al sacrificio de los más educados (impuestos directos) para ayudar a los menos formados.

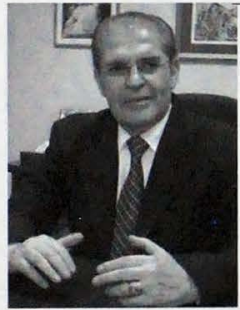

Empezando por una aseveración: "no existe pals que haya logrado un desarrollo integral con bajos niveles de educación"; ésta, definitivamente, es la piedra angular del desarrollo y en el pals se requiere una especie de revolución educacional, más que otra simple reforma, que incremente el nivel promedio nacional de estudios y mejore sustancialmente la calidad de la enseñanza desde los niveles básicos hasta los superiores. El recurso natural y potencial de este paĺs es y seguirá siendo su gente. Una revolución educativa que comprenda una reingeniería de los sistemas de enseñanza es la garantia autentica de crecimiento futuro, por cuanto la educación es un área estratégica en una visión país. La educación secundaria específicamente, la capacitación de la mano de obra y la mejora en todos los niveles educativos son necesarias. Es imperioso que la agenda nacional enf atice ese tema.

Rafael Rodríguez Loucel, UTEC

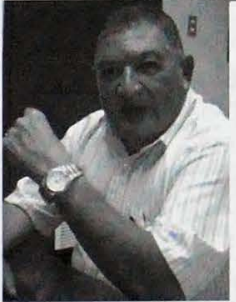

El tema es de suyo, complicado; pero no creo que nadie dude de la importancia que la educación, a todos los niveles, tiene para el futuro de nuestro pais. Pero tan importante como la calidad educativa, que sin lugar a dudas requiere ser mejorada, igualmente lo es la ampliación de ella a todos los sectores y zonas geográficas del pals, a su acceso sin limitaciones, a la capacidad del sistema de of recer facilidades para los que aspiren educarse y superar sus conocimientos. Igualmente importante es el acceso a la cultura, asi en mayúsculas, a la CULTURA, que de je de ser un bien privativo de una elite para convertirse en el día a día de una nación. 


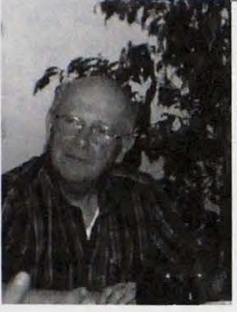

Héctor Dada Hirezl, Diputado COU
La educación es un elemento imprescindible del proceso de desarrollo personal y social. Es el proceso de transferencia de conocimientos y de aprendizaje de la toma de las propias decisiones y del proceso de la producción de conocimientos. Si nos atenemos a los resultados de los servicios educarivos que hay en el país podremos concluir en primer lugar que hay una enorme disparidad en la calidad de la educación entre los distintos entes que la sirven, y además que en promedio la deficiencia es muy notoria. Por otro lado, creo que en general aún la educación universitaria privilegia excesivamente la asimilación de conocimientos ajenos - lo que indiscutiblemente es indispensable - y muy poco los otros dos aspectos. Por otro lado, la educación tiende a estar separada de la vivencia cotidiana de la gente y sobretodo de la historia del país. En resumen, porque de esto pudiera y debiera hablarse largamente, creo que siendo un factor importante para el desarrollo humano, incluido el desarrollo económico, la educación que se da en el pais - pese a algunos avances indiscuribles sobretodo en cobertura - está muy lejos de ser la que se necesita para dar el salto cualitativo que se requiere.

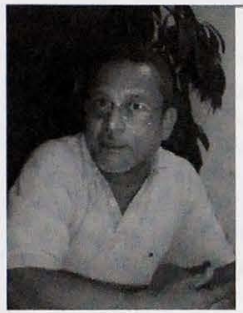

Carlos Briones, FLACSO
Mejorar la educación superior rápido, es crítico. Que las universidades, patrocinadas por la misma empresa privada, pudieran investigar sobre agricultura o demás componentes claves para el desarrollo es muy necesario. Los Estados Unidos quieren apostarle a las frutas exóticas y para citar un ejemplo, en los setenta la fruta Kiwi originaria de Nueva Zelanda era desconocida, de repente, en los ochenta se hizo popular en Europa y posteriormente se ha convercido en una fruta popular a nivel mundial y el máximo exportador no es Nueva Zelanda, sino Chile, que asumió investigar su implantación agrícola y desarrollo comercial. Que pudiéramos nosorros por ejemplo hacer lo mismo con el loroco, o cualquier orra fruta o culrivo tropical, sería fundamental para el desarrollo. Pero para ello se necesita apostarle a la investigación dentro de la educación superior.

El Estado debe mantener la atención tanto en los niveles básicos como en el nivel de educación superior. Porque no puede crearse sólo un nivel superior de capital humano calificado si se tiene una base muy débil a nivel de la cobertura de la educación primaria y limitaciones en el acceso de la población a la educación primaria y secundaria. Asimismo por razones de equidad, deben crearse las condiciones de ciudadanla y oportunidades para todos y eso sólo puedo lograrse si se mantienen a nivel de escuela primaria y secundaria la mayor parte de la población y sobre todo los sectores de menores ingresos.

Pero tampoco puede esperarse que eso madure a veinte años, por eso la educación debe caminarse a dos carriles. Es necesario vigilar a la vez cual es la situación de la estructura universitaria, cual es la relación de la empresa privada y la universidad, cual es la relación del estudiante universitario con la universidad, por que son ellos los que van a tomar las oportunidades ahora, porque en veinte años, no se tendrán las mismas oportunidades.

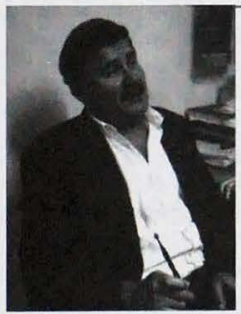

Roberto Rubio, FUNOE
A nivel de cobertura, se ha avanzado bastante en los últimos años, pero toda vía deja mucho que desear la calidad de la educación. Hay discusiones si la calidad debe iniciar en el nivel primario, secundario o superior. Yo no tengo una opinión acabada sobre eso pero, en general, se nota que hay deficiencia en la calidad. Debe existir una educación en términos de la calidad, buscando dar respuestas a ciertas estrategias de desarrollo.

Por ejemplo, si se trae inversión para desarrollar los call centers, se necesitará personas que hablen ingles, si ingresan empresas de computación se necesitará gente capacitada en el ramo, si se va a tener un plan de turismo, necesitaremos especialistas, si se impulsará la pesca, hay que reestablecer el bachillerato de pesca. Tiene que desarrollarse una educación quevaya orientada a esa estrategia. $Y_{\text {al }}$ mismo tiempo, es necesario darle importancia al tema de la calidad. Es cómo enseñarle a la gente a pensar, hacer de la filosofía y sociologla algo importante, porque son materias que han sido descuidadas. No se trata de educar a la gente para que sólo haga dinero, sino que sepa pensar también. Creo que la estrategia que combine ambas áreas, la educación primaria y también la superior, debería ser la apuesta educativa. 